Article

\title{
Optimal Acquisition and Production Policy for End-of-Life Engineering Machinery Recovering in a Joint Manufacturing/Remanufacturing System under Uncertainties in Procurement and Demand
}

\author{
Haolan Liao, Qianwang Deng * and Yuanrui Wang \\ State Key Laboratory of Advanced Design and Manufacturing for Vehicle Body, Hunan University, \\ Changsha 410082, Hunan, China; liaohaolan@hnu.edu.cn (H.L.); wyr_2014@hnu.edu.cn (Y.W.) \\ * Correspondence: deng_arbeit@hnu.edu.cn \\ Academic Editor: Tin-Chih Toly Chen \\ Received: 14 December 2016; Accepted: 20 February 2017; Published: 24 February 2017
}

\begin{abstract}
The intensive shortage of natural resources and the inchoate phase of automobile remanufacturing in a closed-loop supply chain (CLSC) are driving people to take cyclic manufacturing seriously. Aiming at maximizing resource utilization and produce profits, we apply an optimizing mathematical analysis to the modeling of automobile engine remanufacturing in a joint manufacturing system, in which the quantity and quality of procurement, and the demand of the market, are both uncertain. The manufacturer can either produce new products with raw materials or remanufacture the returned product taken back from customers; the raw materials are bought from two suppliers with certain probabilities of disruption in the supply. The returned products are classified into different quality levels according to the testing results after sorting, by considering the remanufacture-up-to strategy we obtained the optimal remanufacturing ratio, then the manufacturing quantity and corresponding maximized total profit of this joint system are determined. We also investigated a real-life case of auto engine remanufacturing, comparing it with the theory of optimal remanufacturing policy, and the results indicate that a material savings of more than $45 \%$ and a cost improvement of more than $40 \%$ could be achieved when the optimal remanufacturing policy of our model is implemented.
\end{abstract}

Keywords: remanufacture; CLSC; cyclic manufacturing; joint system; remanufacture-up-to; optimal policy; uncertainty

\section{Introduction}

In recent decades, with the rapid development of modern industry, resource depletion and energy crises have become increasingly prominent, which is threatening our existence because of excessive natural resource exploitation. People have now realized that the worsening ecological environment becomes an obstacle standing in the way of sustainable industry development. With a large number of vehicles and other items becoming old and increasing waste annually, these end-of-life products are the direct cause for environmental issues. To reduce the negative impacts on the environment and respond to the government's restriction on OEMs, and also to maximize profit, manufacturers have begun to pay attention to the recycling and reusing of waste products. A large number of studies have made contributions to the theory and model of remanufacturing [1-5].

Remanufacturing serves as an industrial secondary manufacturing process whereby end-of-life (EOL) products (cores or hulks) are taken back from customers waiting for a series of processes, such as sorting, testing, dismantling, repairing, disassembling, reusing, refurbishing, recycling, and disposing, by which a product or parts can be restored to their original performance. It is a valued-added process 
that possesses great potential in economic and environmental benefits [6,7]. Since remanufacture is one important process of $3 R$ (recycling, remanufacturing and reusing) in cyclic economy, it is often beneficial for saving materials and is cheaper than producing new ones [8]. The remanufactured items include electronics, machine tools, medical instruments, automobiles and components, construction machinery, and aviation equipment $[9,10]$. For the automobile industry, remanufacturing can save $60 \%$ energy consumption compared with manufacturing on the whole. Over $70 \%$ of the material from end-of-life products can be recycled and the cost is actually reduced by as much as half, and the adverse impact of the environment is significantly reduced. Taking [11] as an example, they have illustrated that remanufacturing of an end-of-life hydraulic valve can restore its function to that of a new one and shorten the lead time, while its cost is reduced by $55 \%$, its resource consumption by $85 \%$, and its material by $90 \%$.

For remanufacturing processes, the CLSC (closed-loop supply chain) possesses huge potential of cost and resource savings. Over the past few decades, plenty of theories and research achievements have emerged over the course of the development of the remanufacturing industry and CLSC. Different strategies and operational aspects of CLSC were researched by those researchers, such as production planning/control, forecasting, inventory management/control, network design, etc. [12]. There are large number of studies and theories on remanufacturing in the automobile industry that are focused on technological processes, state of the art, government subsidy and policy, and some basic theoretical remanufacturing models. In [13] Koyanaka and Kobayashi utilize a 3D camera and a weighing device to improve the automatic sorting technique according to the density and 3D shape, and apply neural network algorithms to the scrap identification to improve the sorting accuracy of end-of-life vehicle (ELV) shredder facilities. Ohno, et al. [14] have proposed a waste input-output material flow model to analyze the automobile composition and evaluate the economic and environmental benefits in an ELV recycling system. By data analysis they conclude that through recycling of AEs, $8.2 \%$ of the annual alloying element consumption was saved in Japan. Kim and Glock [15] have considered a remanufacturing system in which the items from the supplier to the retailer are transported by containers. The containers that are returned from retailers can either be repaired for a second use or disposed in light of their conditions, and by using the RFID method both supply chain information and container return rates are improved. Hjaila, et al. [16] have explored a third-party retailer pricing strategy for a multi-product SC model in which the policy estimation is proposed by using different price approximations and the demand elasticity theory. These studies have primarily put their emphasis on economic efficiency, leaving important problems relating to the equilibrium between the manufacturing and recycling in automobile industries unaddressed.

There is some literature that report studies on production planning, production control, and optimum production strategy. Hjaila, et al. [17] explore stochastic models to evaluate the quantity of procurement. They do no cover the issue of analyzing the optimum production and inventory strategy based on those models. Guo, et al. [18] consider a jointed pricing decision model in a remanufacturing system under uncertain demand from the perspective of a solo manufacturer, for the price of remanufactured products have an effect on newly produced products, the manufacturer has to make a joint price strategy to maximize his profits. The study takes into account the influence of remanufacturing products' WTP to pricing and the uncertainty in demand, and they have built the two-item news-vendor model on the basis of profit maximization, given the Karush-Kuhn-Tucker optimal conditions. However, the uncertainty of the quality in procurement and its influence on the total costs and profits of production need to be further studied. Huang, et al. [19] propose an optimal control policy and concludes that the rates of returned products have a distinct influence on order quantities and profits of the seller. According to the analytic results, the manufacturer should take efficiency measures to lower the returned product rates in a single remanufacturing system (the products are only from returned items). Konstantaras, et al. [20] have built up a joint EOQ and EPQ model in which the stationary demand can be met by both remanufactured and newly-purchased products in a joint remanufacturing system. Teunter, et al. [21] creatively put 
forward a remanufacture-up-to strategy, by which they sort the returned items into different classes according to their quality condition, and then explore a simple closed-form expression for the total expected cost, and optimal newsboy-type solutions for the optimal remanufacture-up-to levels. Finally, through the mathematical model, they decide on a critical value of the remanufacture-up-to level to obtain the optimum production strategy. Those studies are focused on the single remanufacturing system in which the EOL items returned from customers are the only source of their production. Mukhopadhyay, et al. [22] put forward that in a single remanufacturing system, firms are exposed to the risk of supply disruption because of different reasons. There exists the uncertainty in the percentage of how many EOL products can actually meet the quality criteria for remanufacturing. They set up a model of the joint remanufacturing system which has two production sources of new parts and also recycles the EOL products. In the system, the portion of used products that meet the criteria of remanufacturing is unknown, i.e., the remanufacturing yield rate is assumed to be a random variable. They not only analyze the uncertainty in market demand, but also in the yield rate, while in this model the competition of multiple new product supplies, the penalty cost, and the inventory control are not taken into account. Fang, et al. [23] deals with the model of the Cournot competition between two supply chains that are exposed to the risk of supply disruption. In this system a retailer should order the quantity according to its competing retailer's supply situation. Finally, they characterize the optimal wholesale price contracts with a linear penalty under different supply risks and competition scenarios. It provides a reference to the research on competition between multiple supplies in the later joint remanufacturing system. Kumar Jena, et al. [24] consider a joint manufacturing system in which each manufacturer will set his outward (forward) price on new products by predicting the wholesale price of his competitor, and the retailer collects the used product at the inward (reverse) price from the market, then sells the EOL product to the respective manufacturer. By predicting the relevant wholesale price manufacturer can maximize his profit. Although this system does not involve the research on the impact of uncertainty in procurement and market demands on the inventory and penalty costs, it provides a reference for us to study the effect of joint price-making on production strategies in a joint remanufacturing system.

Although a considerable amount of research has been carried out on CLSC, to the best of the authors' knowledge, no attempt has been made to study the impact of supply disruptions in a joint remanufacturing system, and then applied the mathematical model to the real-life production case. Additionally, we also made the comparison between the theoretical analysis and the real situation, and then drew a conclusion of the percentage of costs saving, and material and resource savings, offering useful reference for practical production. Based on the precious studies of our predecessors, in order to provide the guidance and theoretical foundation for manufacturers to obtain higher profits and environmental benefits, further efforts need to be taken in terms of mathematical analysis and remanufacturing models that are more appropriate to the real situation in CLSC.

In addition, compared with the remanufacturing of electronics and small home appliance products, the remanufacturing of automobiles is characterized by its long production period, complex procedures, and multi-factor uncertainty. Berzi, et al. [25] have investigated the process of end-of-life vehicle remanufacturing in authorized treatment facilities (ATFs) in Italy. Goepp, et al. [26] consider the remanufacturing model from the phase of product design. Rebitzer and Tang, et al. $[27,28]$ have conducted a theoretical analysis of a joint remanufacturing system in which the lead times are taken as stochastic, but the return and demand as constant. Kleineidam, et al. [29] considered a model in which the demand of remanufactured products decreases with the increase of the selling price and the supply increases with the increase of the selling price and the equilibrium of the market is obtained through the intersection of the two curves. Few studies available analyze the joint remanufacturing system of automobiles, taking the uncertainty both in procurement and demand into consideration, and failing to put up a model more appropriate to the real situation for further reference. Giri, et al. [12] considered a closed-loop supply chain (CLSC) inventory system assuming the market demand and the procurement are both stochastic. In this joint manufacturing system, the manufacturer produces new 
products with raw materials from two suppliers and also remanufactures the end of life products taken back from a collector. They do not take the uncertain quality factor of procurement into consideration and that uncertainty in quality will lead to cost errors of acquired items according to [21]. Except for this, the model in [12] is comparatively appropriate to the real situation. Along this line, we extended a joint remanufacturing model to take the uncertainty in acquired products into consideration aiming at addressing this gap; in particular, in this model of the automotive remanufacturing industry, we focus on the mathematical method of the problem of the economic order quantity in a joint system based on the model evolved in light of the actual situation of the Chinese remanufacturing environment. By utilizing the conceptualization of the multi-quality fraction of EOL products, we then proposed a mathematical model of this joint system and made an analysis of a situation more appropriate to the real practice, in which the quality of procurement and demand follow a certain statistical distribution, as long as the acquisition quantity is large enough, the random variable of procurement quality follows the normal distribution according to the center limit theorem of mathematical statistical theory. By reasonable mathematical analysis we derived an optimal procurement quantity and remanufacturing strategy under the premise of profit maximization.

The remainder of this paper is organized as follows: in Section 2, the model of our problem is defined. In Section 3, the model is developed to further consider the optimal acquisition quantity decision to obtain the optimal solution of profit maximization. In Section 4, we provide numerical experiments to illustrate the feasibility of our proposed mathematical model, by which we derive the optimal quantity and remanufacturing strategy of procurement for the joint remanufacturing system. Then, using this theoretical model as guidance, we compared a real-life case in automobile engine remanufacturing. In Section 5 we end with some conclusions.

\section{Model Description and Formulation}

We define the variables with a set of concise and inerratic symbols. For the ease of writing, we make some general rules for the symbols, such as $Q$ denotes quantity, $C$ denotes cost, superscript $\mathrm{r}$ denotes remanufacturing, subscript $k$ denotes the quality level; e.g., $Q_{k}^{r}$ denotes the quantity of remanufactured cores and that their quality level is $k$ (hereafter we will refer to them as "cores of quality $\left.k^{\prime \prime}\right), C_{k}^{r}$ denotes the unit remanufacturing cost for cores of quality $k$, and $Q_{*}^{m}$ denotes the optimal quantity of manufactured cores, etc. (as shown in Table 1).

Table 1. Notations used.

\begin{tabular}{cc}
\hline Notations & Description \\
\hline$Y$ & Random variable of acquisition quantity \\
$X$ & Random variable of customers demand \\
$r_{d}$ & Remanufacture rate \\
$h(x, y)$ & Joint probability density function of acquisition and demand \\
$k$ & Random variable of quality level, $k=1,2,3, \ldots$ \\
$C^{m}$ & Unit manufacturing cost \\
$C^{M}$ & Total manufacturing cost \\
$C^{r}$ & Unit remanufacturing cost \\
$C^{R}$ & Total remanufacturing cost \\
$C^{h}$ & Holding cost for unit core \\
$C^{p}$ & Penalty cost for unit unsatisfied demand \\
$C^{a}$ & Acquisition cost for unit core \\
$C_{k}^{r}$ & Anit remanufacturing cost for the cores of quality $k, k=1,2,3, \ldots$ \\
$Q^{a}$ & Acquisition quantity of returned cores \\
$Q^{m}$ & Manufacturing quantity \\
$Q_{*}^{a}$ & Optimal quantity of acquisition \\
$P^{T}$ & Total production profit \\
$P^{s}$ & Unit salvage value \\
\hline
\end{tabular}




\subsection{Model Description and Formulation}

In this paper, a joint manufacturing/remanufacturing system is proposed in which the demand of customers can either be met with new products or remanufactured products. We assume that there is no difference between remanufactured and new products in performance and application, and the system discards no returned cores, though it is some times more profitable because of the subsidy policies in China for the vehicle remanufacturing industry. However, that is beyond the scope for this paper, and we only assume that each returned core of quality $k$ is capable of remanufacturing and the cost is $C_{k}^{r}$. The core returned from customers can also be sold in a second market for dismantling, its salvage value is denoted as $P^{s}$.

We consider a joint remanufacturing system (shown in Figure 1) for a single product in which there is one serviceable inventory for the remanufactured products, the shortage of remanufactured products can be replenished by newly manufactured ones for both the uncertainty in demand and acquisition, and there are two raw material suppliers in this system. The first supplier is considered as the regular supplier and the secondary one as the alternative. The regular supplier is cheaper in price, but unreliable in the supply capacity, and there exists a chance of supply disruption with a probability of $P$. For the second one, it is comparatively expensive, but completely reliable, any demand of raw materials can be met with no supply disruption. The assumption is consistent with some literature [30-32], and Ahiska, et al. [33] reckon that multi-suppliers are preferred by firms even under no risk of supply disruptions to obtain better responsiveness and faster supply because of the high punishing cost for the unsatisfied demand. It is often the case that the firms purchase the major part of their materials from the regular supplier with a longer lead time, and turn to the alternative one with expedited service when needed in spite of the high price.

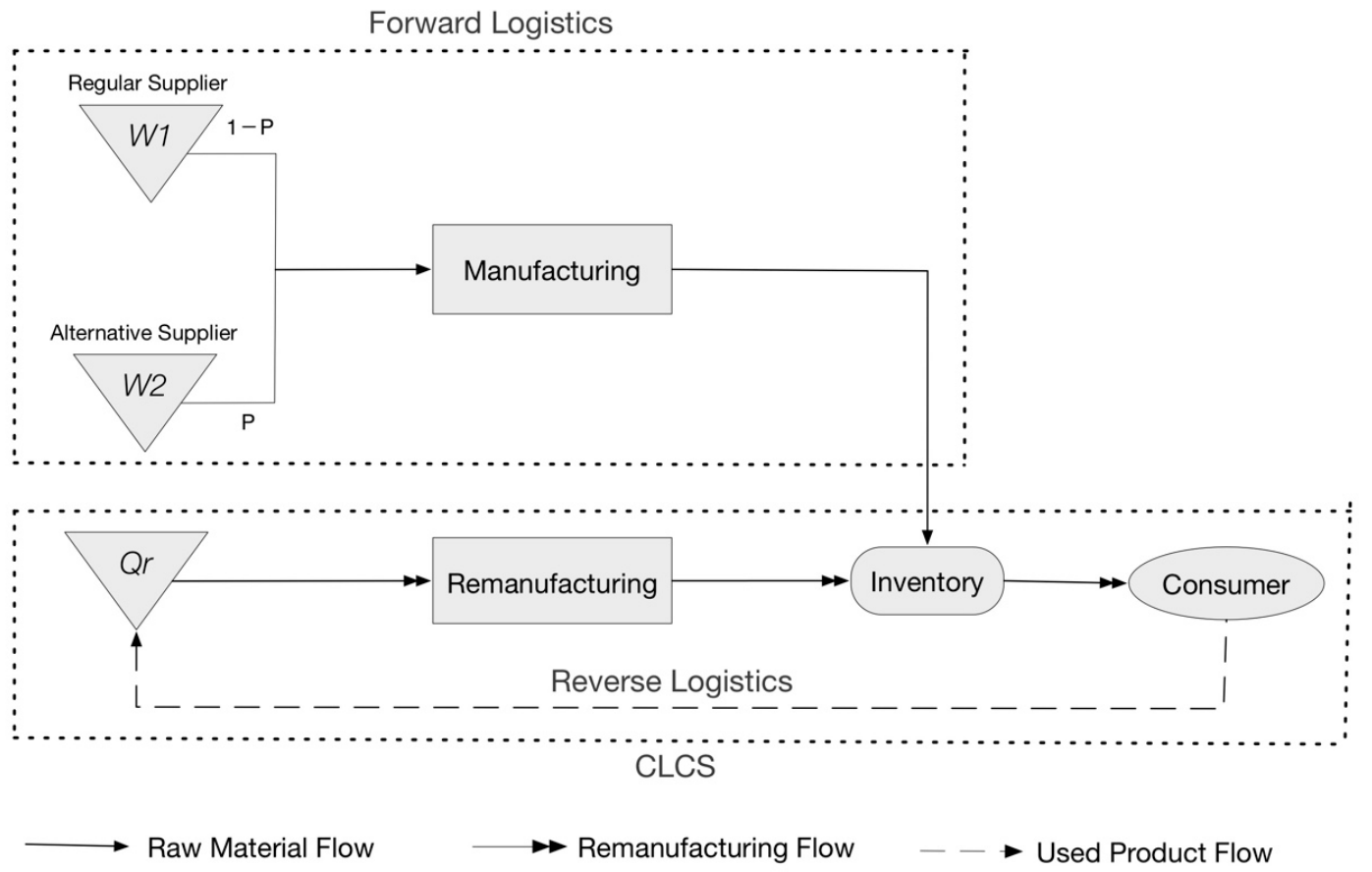

Figure 1. Framework of the joint remanufacturing system.

\subsection{Decompose the Problem into a Series of Smaller Ones}

Based on the abovementioned framework, the objective of this model can be subdivided into several aspects:

- How many end-of-life products need to be purchased? 
- How many new products should be manufactured?

- How much the optimal selling price should be set as?

- How many end-of-life products of quality $k$ should be remanufactured?

- How many of the total products should be sold and how many be stocked?

\subsection{Model Definition}

The expected remanufacture cost is:

$$
C^{R}=C^{r} r_{d} E[Y]=C^{r} r_{d} \int_{0}^{\infty} y g(y) d y
$$

where $C^{r}$ denotes the cost of remanufacture and $r_{d}$ remanufacture rate, and $g(y)$ is the probability density function of the quantity of procurement. Then the expected acquisition $\operatorname{cost} C^{A}$ of returned product is:

$$
C^{A}=C^{a} E[Y]=C^{a} \int_{0}^{\infty} y g(y) d y
$$

Then the expected total cost of the joint manufacturing can be expressed as:

$$
C^{T}=(1-P) w_{1} Q^{m}+P w_{2} Q^{m}+C^{m} Q^{m}+C^{r} r_{d} \int_{0}^{\infty} y g(y) d y+C^{a} \int_{0}^{\infty} y g(y) d y
$$

and the expected underage $\operatorname{cost} C^{P}$ as:

$$
C^{P}=C^{p} E\left[X-Q^{m}-r_{d} Y\right]^{+}=C^{p} \int_{0}^{\infty} \int_{Q^{m}+r_{d} y}^{\infty}\left(x-Q^{m}-r_{d} y\right) h(x, y) d x d y
$$

The expected overage $\operatorname{cost} C^{H}$ as:

$$
C^{H}=C^{h} E\left[Q^{m}+r_{d} Y-X\right]^{+}=C^{h} \int_{0}^{\infty} \int_{0}^{Q^{m}+r_{d} y}\left(Q^{m}+r_{d} y-x\right) h(x, y) d x d y
$$

The expected revenue as:

$$
P^{r} E\left[\min \left(X, Q^{m}+r_{d} Y\right)\right]=P^{r}\left(\int_{0}^{\infty} \int_{0}^{Q^{m}+r_{d} y} x h(x, y) d x d y+\int_{0}^{\infty} \int_{Q^{m}+r_{d} y}^{\infty}\left(Q^{m}+r_{d} y\right) h(x, y) d x d y\right)
$$

Finally, we obtained the expected total profit of the joint system as:

$$
\begin{aligned}
& P^{T}=P^{S}\left(1-r_{d}\right) \int_{0}^{\infty} y g(y) d y+P^{r}\left(\int_{0}^{\infty} \int_{0}^{Q^{m}} x h(x, y) d x d y+\int_{0}^{\infty} \int_{Q^{m}+r_{d} y}^{\infty}\left(Q^{m}+r_{d} y\right) h(x, y) d x d y\right) \\
& -\left[(1-P) w_{1} Q^{m}+P w_{2} Q^{m}+C^{m} Q^{m}+C^{m} r_{d} \int_{0}^{\infty} y g(y) d y+C^{m} \int_{0}^{\infty} y g(y) d y\right. \\
& \left.-C^{p} \int_{0}^{\infty} \int_{Q^{m}+r_{d} y}^{\infty}\left(x-Q^{m}-r_{d} y\right) h(x, y) d x d y-C^{h} \int_{0}^{\infty} \int_{0}^{Q^{m}+r_{d} y}\left(Q^{m}+r_{d} y-x\right) h(x, y) d x d y\right]
\end{aligned}
$$


The objective of this study is to find the optimal value of $Q_{*}^{m}$ that maximizes $P^{T}$. When the random variable of market demand $X$ and the random variable of acquisition quantity $Y$ both follow the exponential distribution, this is consistent with [34,35], and their density functions are:

$$
f(x)=\left\{\begin{array}{c}
\lambda e^{-\lambda x} \text { for } x>0 \\
0, \text { otherwise }
\end{array}\right.
$$

and

$$
g(y)=\left\{\begin{array}{c}
\mu e^{-\mu y} \text { for } y>0 \\
0, \text { otherwise }
\end{array}\right.
$$

where $\lambda, \mu>0$, the expected total profit $P^{T}$ of this joint system is denoted as:

$$
\begin{gathered}
P^{T}=\frac{P^{s}\left(1-r_{d}\right)}{\mu}+P^{r} \frac{\left(r_{d} \lambda+\mu\right)-e^{-Q \lambda} \mu}{\lambda\left(r_{d} \lambda+\mu\right)}-\left[(1-P) w_{1} Q^{m}+P w_{2} Q^{m}+C^{m} Q^{m}+\frac{C^{r} r_{d}}{\mu}+\frac{C^{a}}{\mu}\right] \\
-C^{p} \frac{e^{-Q \lambda} \mu}{\lambda\left(r_{d} \lambda+\mu\right)}-C^{h}\left[Q^{m}+\frac{r_{d}}{\mu}+\frac{e^{-Q \lambda} \mu-\left(r_{d} \lambda+\mu\right)}{\lambda\left(r_{d} \lambda+\mu\right)}\right]
\end{gathered}
$$

From Equation (8), it is easy to deduce that:

$$
\frac{d^{2} C^{T}}{d\left(Q^{m}\right)^{2}}=-\frac{e^{-Q \lambda}\left(C^{h}+C^{p}+P^{r}\right) \lambda \mu}{\left(r_{d} \lambda+\mu\right)}<0
$$

Hence, the profit expression $P^{T}$ is the concave function of $Q^{m}$. The optimal quantity of manufacturing $Q_{*}^{m}$ is derived as:

$$
Q_{*}^{m}=\frac{1}{\lambda} \log \left[\frac{\left(C^{h}+C^{p}+P^{r}\right) \mu}{\left[C^{m}+C^{h}+(1-P) w_{1}+P w_{2}\right]\left(r_{d} \lambda+\mu\right)}\right]
$$

Equation (9) indicates that the optimal manufacturing quantity $Q_{*}^{m}$ decreases with the increase of the yield rate of acquisition. The result is intuitive because the higher the value of $r_{d}$ goes up, the less the quantity of new products is required for the manufacturing process.

\section{Illustration of the Proposed Method}

In the process of remanufacturing, the difference of the quality level will result in significant differences in the process routes and lead times, which directly leads to an increase of the remanufacturing cost. Therefore, it can significantly help reduce the complexity and generate more rewards to establish a classified formula for the quality level according to the testing results, and then remanufacture the cores of the same quality with the same process route [36]. Teunter and Flapper [21] have proposed a remanufacturing-up-to level definition along with the idea of an order-up-to concept. In a real-life scenario, the distribution of quality levels in a lot of acquired products is unknown until being cleaned and tested. As mentioned, the high quality of a core means the low cost of remanufacturing, for some cores in poor condition their repairing and remanufacturing costs are likely higher than a new product, and it is intuitive that we only remanufacture those cores whose remanufacturing cost is lower than a new product and sell the rest to the second market for dismantling and other industrial purposes. Therefore, once the quality levels in a lot of cores are determined, the best policy is often to remanufacture the cores from the high rank to the low, by utilizing the news-boy method, and by considering the acquisition and processing cost we can uniquely determine a value of remanufacturing-up-to quality level $k$ to obtain the optimal total profit. 


\subsection{Optimal Remanufacturing Quantity}

The quality level $k$ of each core is uncertain, and we assume that a random variable $K$ follows a multinomial distribution with probability $P_{i}$ (core of quality $i, i=1,2, \ldots$ ). The assumption is appropriate when the quality values of cores in an acquired lot are independent, which is often the case for remanufacturing [37].

$$
r_{d}=\sum_{i=1}^{k} p_{i}=\frac{Q^{a} \sum_{i=1}^{k}\left(\begin{array}{c}
Q^{a} \\
k
\end{array}\right) p^{k}(1-p)^{Q^{a}-k}}{Q^{a}}=\sum_{i=1}^{k}\left(\begin{array}{c}
Q^{a} \\
k
\end{array}\right) p^{k}(1-p)^{Q^{a}-k}
$$

let:

$$
\eta_{n}=Q^{a} \sum_{i=1}^{n} p_{i}, n \rightarrow \infty
$$

where $k$ is an integer variable over an interval of $\left(0, Q^{a}\right)$, based on the central limit theorem, when $Q^{a}=n \rightarrow \infty, k$ can be taken as a continuous variable; then $\eta_{n}=\sum_{i=1}^{n} Q^{a} \cdot p_{i}$ follows the normal distribution.

$$
\begin{aligned}
r_{d}=\lim _{n \rightarrow \infty} P\left\{\frac{\eta_{n}-n p}{\sqrt{n p(1-p)}}\right. & \left.\leq \frac{\sum_{i=1}^{k} p_{i}-p}{\sqrt{p(1-p)} / \sqrt{n}}\right\}=\int_{-\infty}^{\frac{\sum_{i=1}^{k} p_{i}-p}{\sqrt{p(1-p) / \sqrt{n}}}} \frac{1}{\sqrt{2 \pi}} e^{-t^{2} / 2} d t \\
& =\Phi\left(\frac{\sum_{i=1}^{k} p_{i}-p}{\sqrt{p(1-p)} / \sqrt{n}}\right)
\end{aligned}
$$

\subsection{Optimal Manufacturing Quantity}

In practical production, the higher the quality rank (the smaller $k$ gets) of the returned product, the lower the cost will be in remanufacturing, i.e., $C_{1}^{r}<C_{2}^{r}<C_{3}^{r}<C_{Q^{a}}^{r}$. It is intuitively insightful that when the $k$ reaches a certain high value the remanufacturing cost is higher than manufacturing. As a consequence, remanufacturing is not profitable for extremely poor-condition end-of-life products, which means a high cost of repairing, component changing, and processing. Therefore, there is a remanufacturing-up-to level $k$ by which we remanufacture the end-of-life products to obtain the maximized resource utility and profit. We used $r_{d}$ derived by $k$ in Equation (11), and the corresponding $Q_{*}^{m}$ is our target value.

$$
Q_{*}^{m}=\frac{1}{\lambda} \log \left[\frac{\left(C^{h}+C^{p}+P^{r}\right) \mu}{\left[C^{m}+C^{h}+(1-P) w_{1}+P w_{2}\right]\left(\Phi\left(\frac{\sum_{i=1}^{k} p_{i}-p}{\sqrt{p(1-p)} / \sqrt{n}}\right) \lambda+\mu\right)}\right]
$$

\section{Numerical Experiments and Real-Life Case Analysis}

In Section 4, we analyze some examples numerically to gain insight into the optimal method of the remanufacturing policy. Then we estimate the effect of remanufacturing optimization inspired by a real-life case. Finally, making a comparison between the real-life case and the theoretical optimal value, the conclusion of the analysis can be taken as the guidance for the practical production.

\subsection{Impact Analysis of System Variables}

\subsubsection{Example 1}

Here we estimate the relationships between system variables to obtain the different contributions made by return rate, demand expectation, and remanufacture-up-to level. Set $P=0.65, P^{s}=60, C^{r}=15$, $C^{m}=11, C^{a}=70, C^{p}=22, C^{h}=7, P^{r}=260, w_{1}=100, w_{2}=140, \mu=1 / 1550$, and $\lambda=1 / 1850$. 
According to Equation (10), assume the value of $r_{d}$ varies from 0.5 to 1 , then the relationship between $Q_{*}^{m}$ and $r_{d}$ is as shown in Figure 2 .

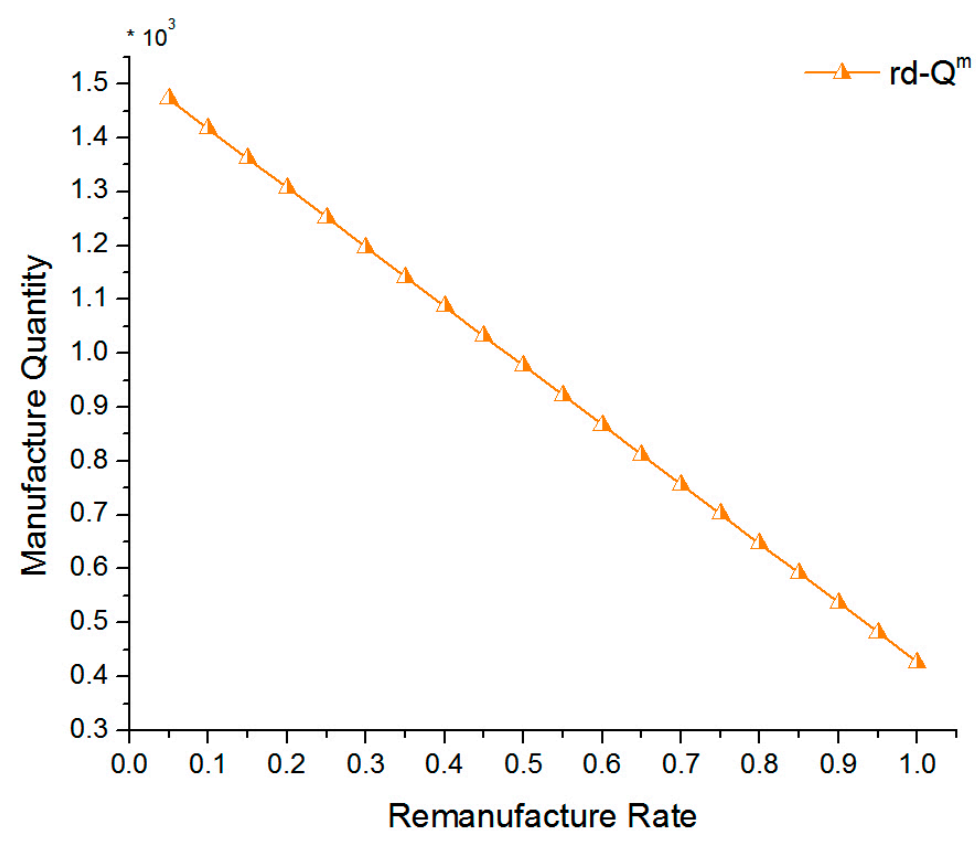

Figure 2. The functional relationship graphic between $Q_{*}^{m}$ and $r_{d}$.

Figure 2 demonstrates that the optimal manufacturing quantity $Q_{*}^{m}$ decreases linearly as the yield rate $r_{d}$ increases. This is because when the yield rate is increased, the quantity of returned products used for remanufacturing increases, and the optimal manufacturing quantity decreases accordingly.

The relationship between $P_{*}^{T}$ and $r_{d}$ is shown in Figure 3 .

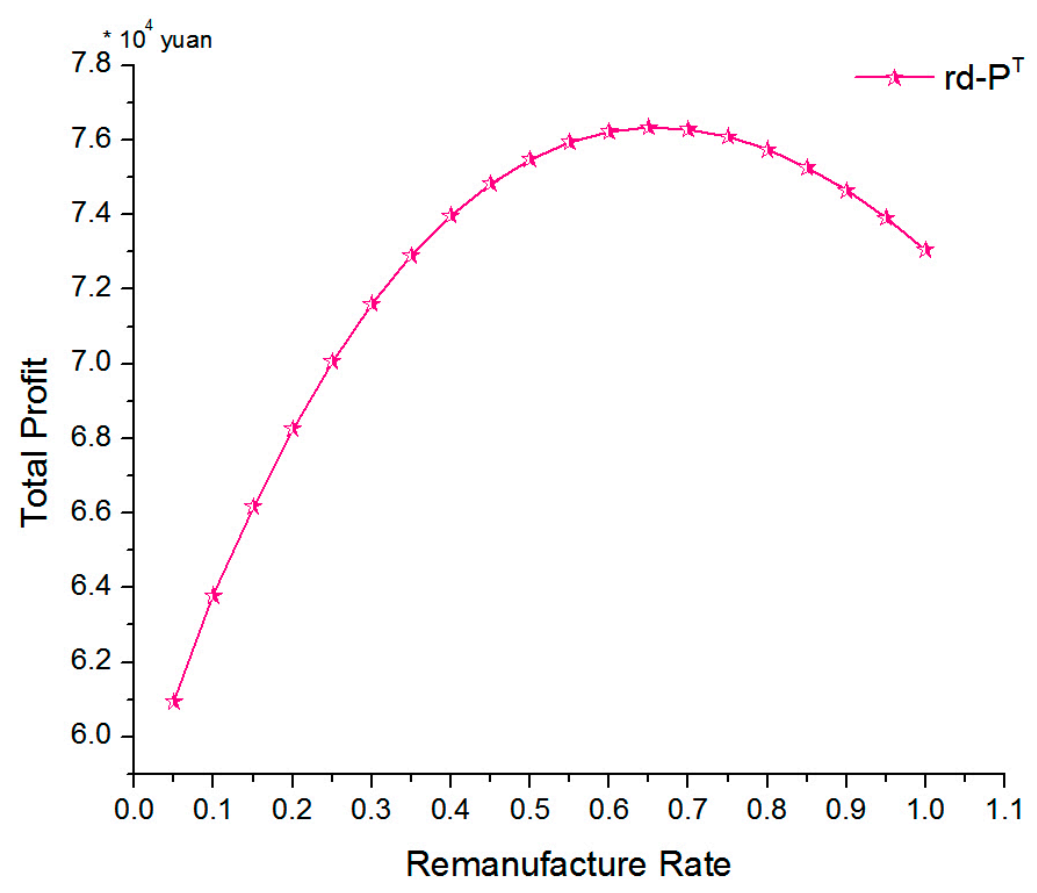

Figure 3. The functional relationship graphic between $P_{*}^{T}$ and $r_{d}$. 
Figure 3 shows that the case of exponential distribution of the total profit is increased as $r_{d}$ increases in the initial stage, but after reaching the maximum value it begins to decrease as $r_{d}$ continues to increase at the end of the stage. The point at which total profit reaches the maximum value is what we are searching for.

\subsubsection{Example 2}

We set $r_{d}=0.55, P=0.35, P^{s}=350, C^{r}=15, C^{m}=200, C^{a}=700, C^{p}=220, C^{h}=70, P^{r}=2600$, $w_{1}=1000, w_{2}=1400, \mu=1 / 1750, \lambda=1 / 2450$. The relationship between $P_{*}^{T}$ and $C^{r}$ is shown in Figure 4 .

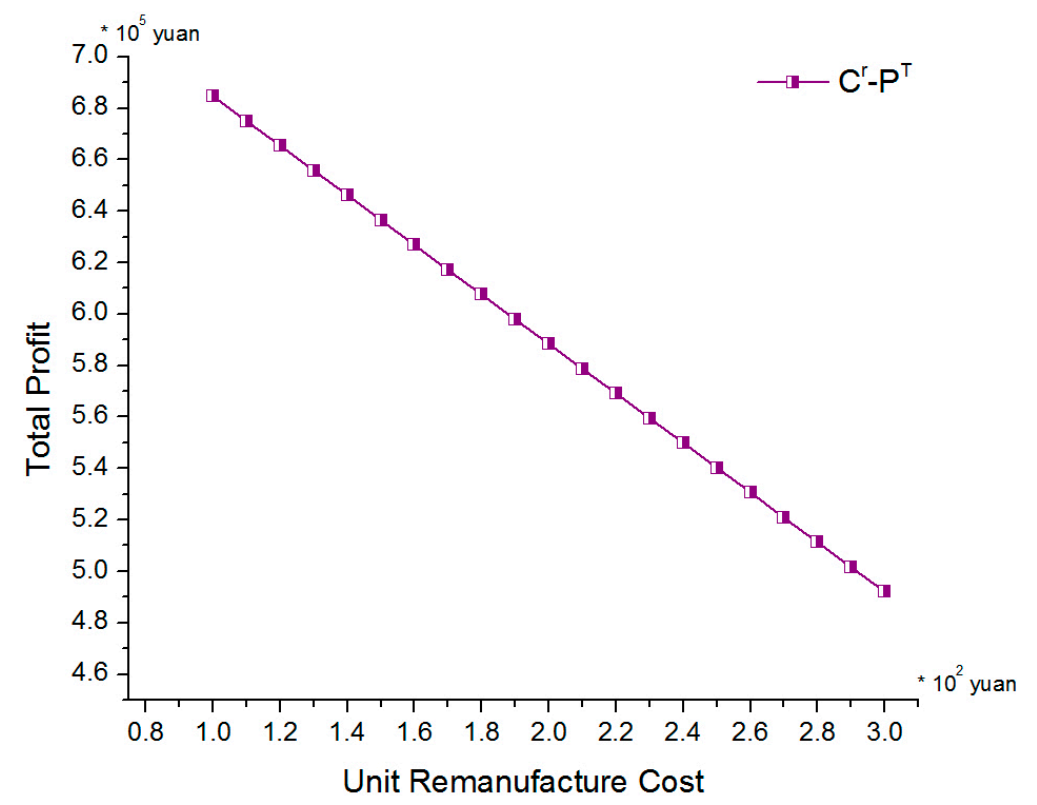

Figure 4. The functional relationship graphic between $P_{*}^{T}$ and $C^{r}$.

The relationship between $P_{*}^{T}$ and $P^{r}$ is shown in Figure 5 .

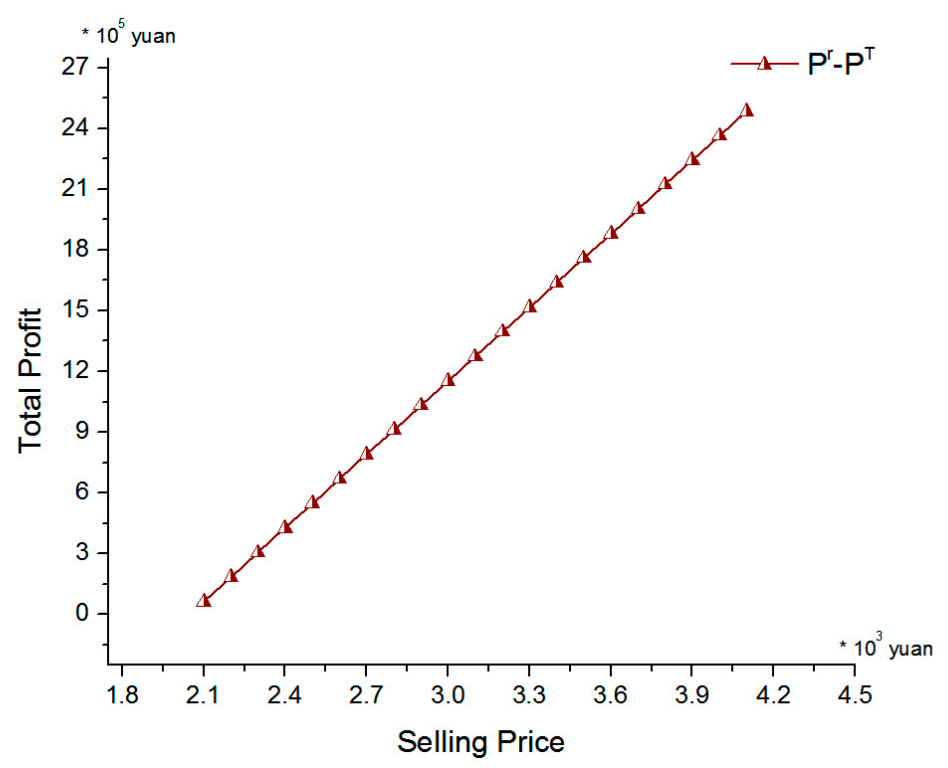

Figure 5. The functional relationship graphic between $P_{*}^{T}$ and $P^{r}$. 
From Figures 4 and 5, it can be observed that the total profit $P_{*}^{T}$ is decreased as the unit $\operatorname{cost} C^{r}$ increases. This is intuitive because that unit cost increase means that the total cost is higher, and the total profit equals to the total revenue minus the total costs. In a similar way, the total profit $P_{*}^{T}$ is increased as the selling price $P^{r}$ increases.

The relationship between $Q_{*}{ }^{m}, Q_{*}^{r}$ and $P^{r}$ is shown in Figure 6 .

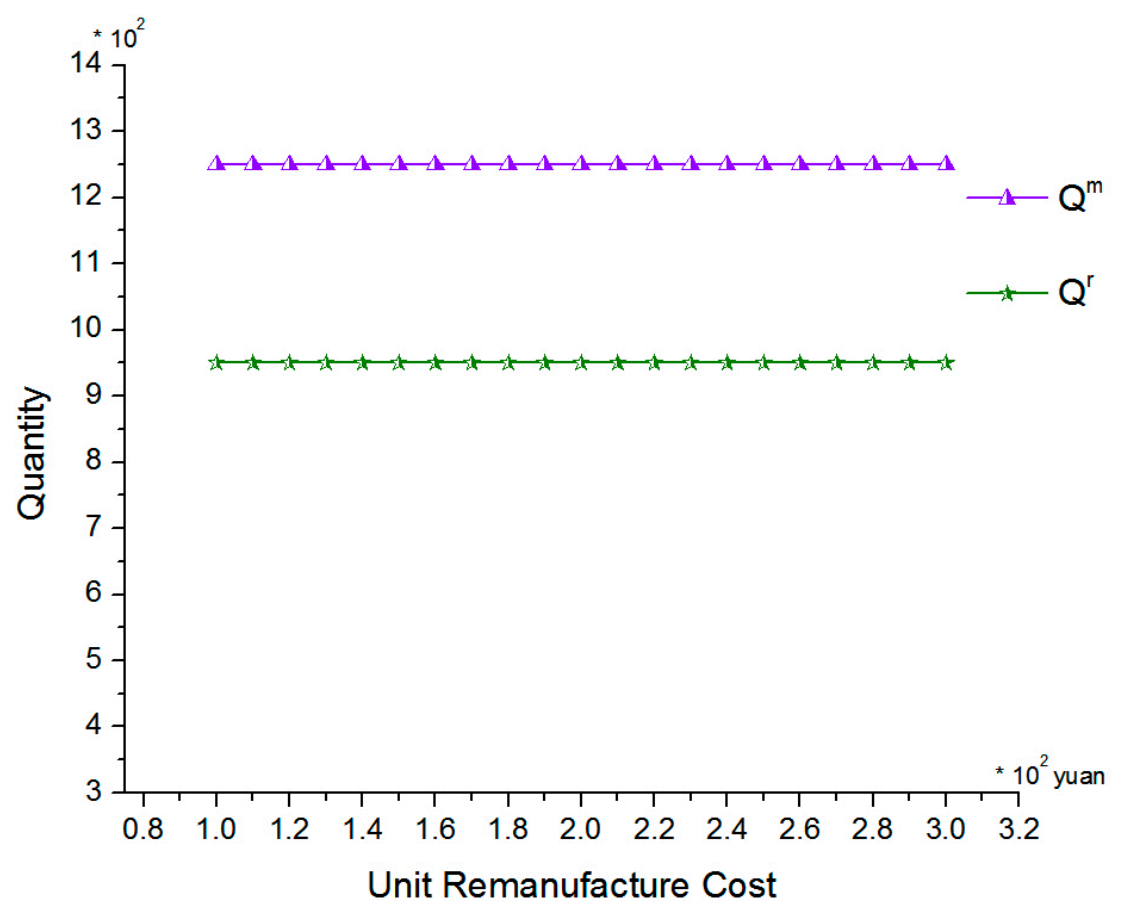

Figure 6. The functional relationship graphic between $Q_{*}^{m}, Q_{*}^{r}$ and $P^{r}$.

\subsection{Real-Life Case Analysis}

In accordance with the theoretical analysis, we apply this model to the real-life case. Based on the data provided by a certain firm in Shanghai engaging in remanufacturing of automobile engines named the Santana X electronic fuel injection engine, we set an appropriate model and perform an analysis of its remanufacturing state. In this model the unit cost of remanufacturing from the life cycle perspective is shown in Table 2.

Table 2. Details of expenditure in remanufacture of the real-life case.

\begin{tabular}{ccc}
\hline \multicolumn{3}{c}{ Remanufacturing Cost (Yuan/Engine) } \\
\hline \multirow{2}{*}{ Material costs } & components & 1530 \\
& end-of-life engine & 1900 \\
\hline \multirow{2}{*}{ Subsidiary material cost } & cleaning agent & 8 \\
& wood & 12 \\
& lubricant & 6 \\
Fuel expense & others & 15 \\
& power fare & 514.07 \\
& water fee & 0.379 \\
& gasoline & 2.73 \\
\hline \multirow{2}{*}{ Others } & labor cost & 423 \\
& managerial fee & 108.57 \\
Total & salvage material & -42.25 \\
\hline
\end{tabular}


In the practical production process, those Santana $X$ electronic fuel injection engines are mainly transported from Beijing, Zhejiang Province, and Henan Province, into Shanghai. Its annual shipments are from 2000 to 4500 engines, the unit transportation is 0.1582 yuan/kilometer. The details of practical production expenditure are shown as Table 3.

Table 3. The practical production expenditure in the real-life case.

\begin{tabular}{cc}
\hline \multicolumn{2}{c}{ Total Cost (Yuan/Per Engine) } \\
\hline Transportation cost(backward) & 396.92 \\
Remanufacturing cost & 4476.70 \\
Cost of capital and depreciation & 87.09 \\
Selling cost & 314.00 \\
Transportation cost(forward) & 396.92 \\
Total & 5671.63 \\
\hline
\end{tabular}

According to the actual situation, the production of this firm is about 2400 engines for the first year, 2800 the second, 3300 the third, and 3500-4500 annually in the rest of the years. All engines that are remanufactured are sold out, and the net profit is shown in Table 4.

Table 4. The total profit of end-of-Life engine remanufacturing in the real-life case.

\begin{tabular}{ccccccc}
\hline \multicolumn{6}{c}{ Total profit of end-of-Life Engine Remanufacturing } & $\left(\times \mathbf{1 0}^{\mathbf{6}}\right.$ Yuan $)$ \\
\hline Year & 1 & 2 & 3 & 4 & 5 & 6 \\
Net profit & 2.113 & 3.170 & 4.284 & 5.747 & 5.503 & 5.764 \\
Year & 7 & 8 & 9 & 10 & 11 & 12 \\
Net profit & 5.346 & 6.055 & 5.980 & 6.4551 & 5.390 & 6.219 \\
\hline
\end{tabular}

Through the data collected we can calculate the Santana X electronic fuel injection engine is sold at the price of 12,600 yuan (average price), e.g., its annual sales are 6000, then the corresponding net profit is $6.354 \times 10^{6}$ yuan.

Combining the actual situation, we deduce that $r_{d}=0.55$ by Equation (10), and $P^{s}=1100$, $C^{r}=3771.63, C^{m}=3200, C^{a}=1900, C^{p}=600, C^{h}=180, P^{r}=12,600, w_{1}=4550$, and $w_{2}=5100$.

Then the corresponding net profits, $Q^{r}$ and $Q^{m}$ are deduced as shown in Table 5.

Table 5. The corresponding net profits of manufacture and remanufacture in the real-life case.

\begin{tabular}{cccccc}
\hline Year & Net Profit $\times \mathbf{1 0}^{\mathbf{6}}$ Yuan & $Q^{r}$ & $Q^{\boldsymbol{m}}$ & $\mathrm{E}[\mathbf{X}]$ & $\mathrm{E}[\mathrm{Y}]$ \\
\hline 1 & 2.470 & 2375 & 360 & 6550 & 4750 \\
2 & 4.189 & 3450 & 886 & 6550 & 5750 \\
3 & 5.435 & 3163 & 1127 & 7550 & 5750 \\
4 & 6.338 & 3326 & 1457 & 8550 & 6050 \\
5 & 6.728 & 3493 & 1564 & 9050 & 6350 \\
6 & 7.082 & 3713 & 1630 & 9550 & 6750 \\
7 & 7.145 & 3768 & 1636 & 9650 & 6850 \\
8 & 7.457 & 3826 & 1754 & 10,000 & 6950 \\
9 & 7.734 & 3850 & 1870 & 10,300 & 7000 \\
10 & 7.896 & 3905 & 1920 & 10,500 & 7100 \\
11 & 8.154 & 3960 & 2020 & 10,800 & 7200 \\
12 & 8.316 & 4015 & 2068 & 11,000 & 7300 \\
\hline
\end{tabular}

4.2.1. Comparison of the Joint Remanufacturing System with Single Remanufacturing of Real-life Case

The comparison between actual value $P^{T}$ and the theoretical optimum value $P_{*}^{T}$ is shown in Figure 7. 


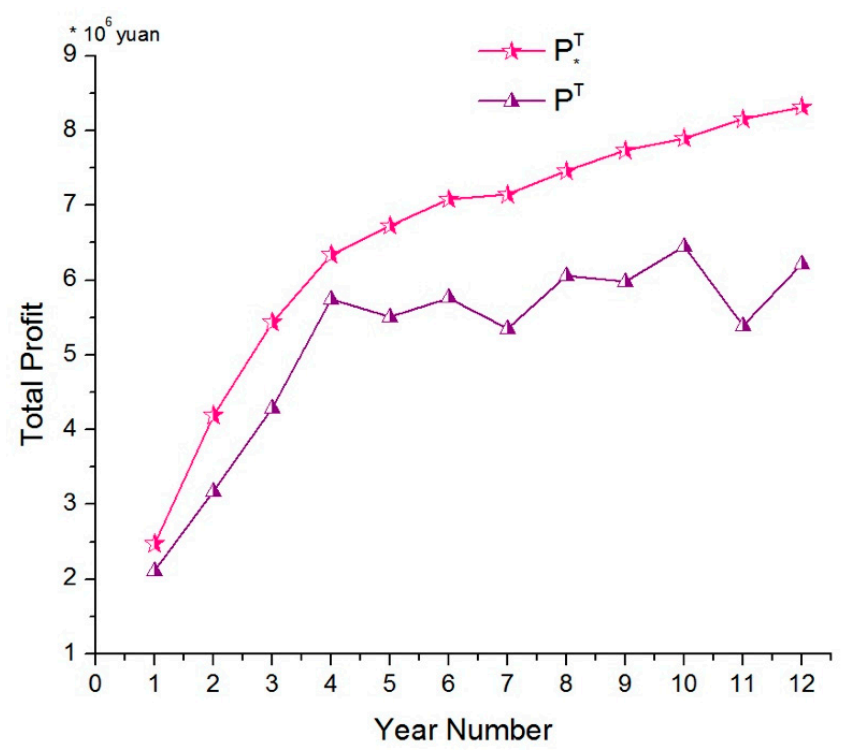

Figure 7. The comparison between actual value $P^{T}$ and the theoretical value $P_{*}^{T}$.

It can be observed that the total profit of our theory model is comparatively higher than that in the real-life case. That is because the single remanufacturing system is not as good at adjusting their production quantity to the fluctuation of market demand as a joint system, leading to the higher cost of penalty $\operatorname{cost} C^{p}$. This fully proves the necessity of building the model of joint remanufacturing system in this paper, through the results of simulation for this model we can find out that the profits and the production costs of remanufacturing system in this real-life case have a room to improve, which provides appropriate guidance for the modern industrial process.

From our theory model we can calculate the optimum quantity of manufacturing and remanufacturing for the joint remanufacturing system, as shown in Figure 8.

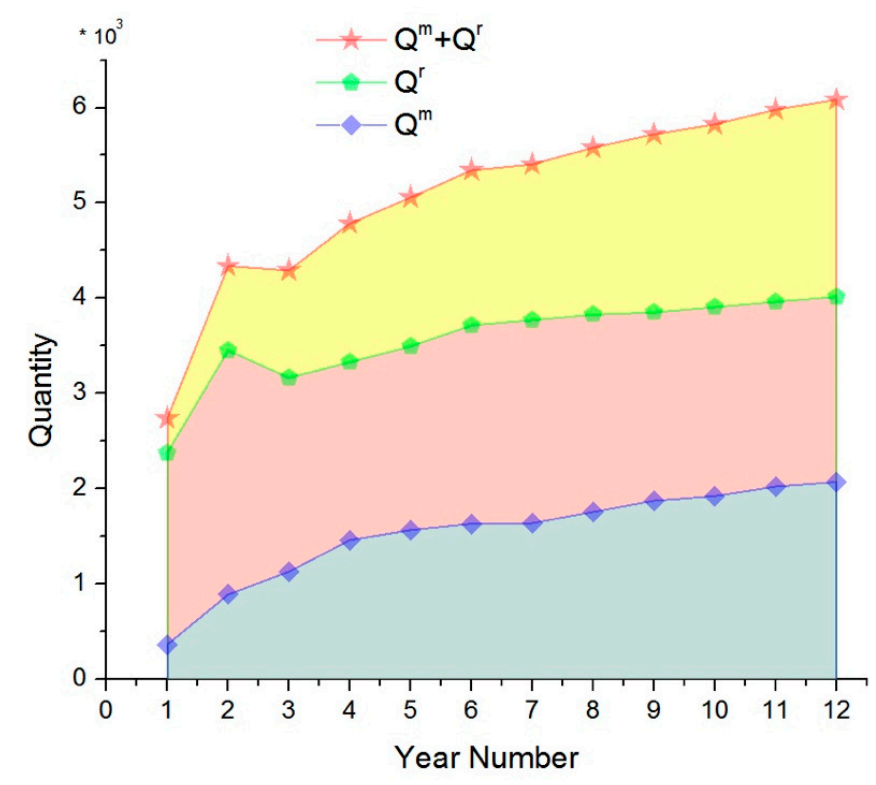

Figure 8. The relationship between $Q^{m}, Q^{r}$ and $Q^{m}+Q^{r}$ for the theory model.

By comparing the theoretical quantity of production in our model with that of the real-life case, we can obtain the relationship graph of them shown as Figure 9. 


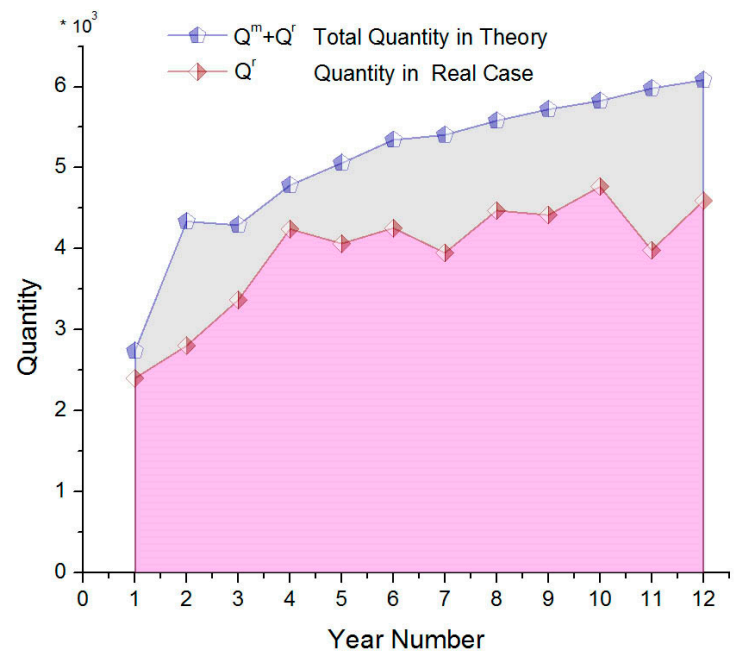

Figure 9. The quantity of remanufacturing in real case and in theory.

Due to the inadequate capacity of adjusting to the market demand in a single manufacture system, the penalty cost is higher than joint system and its total profit is lower. This can be explained from the quantity of production in both systems.

Generally speaking, compared with the single remanufacturing system, the joint system is more capable of adjusting production to the optimum quantity and lowering the cost, tending to gain more profits than the single remanufacturing system when the other conditions are kept constant.

\subsubsection{Comparison of the Remanufacture with Manufacture}

As mentioned above, the cost of remanufactured engines are reduced by $55 \%$, resource consumption by $85 \%$, and material by $90 \%$. Under the same production or net profit, compared with the single manufacturing system (original equipment manufacturer, OEM), the cost reduction, and the resource and material savings, can be quantified in our real-life remanufacturing system, which are calculated as percentages and shown graphically as bar graphs.

Figure 10 shows, when under the same profit, the percentage of saved costs of the remanufacturing system compared to that of the single manufacturing system for each year.

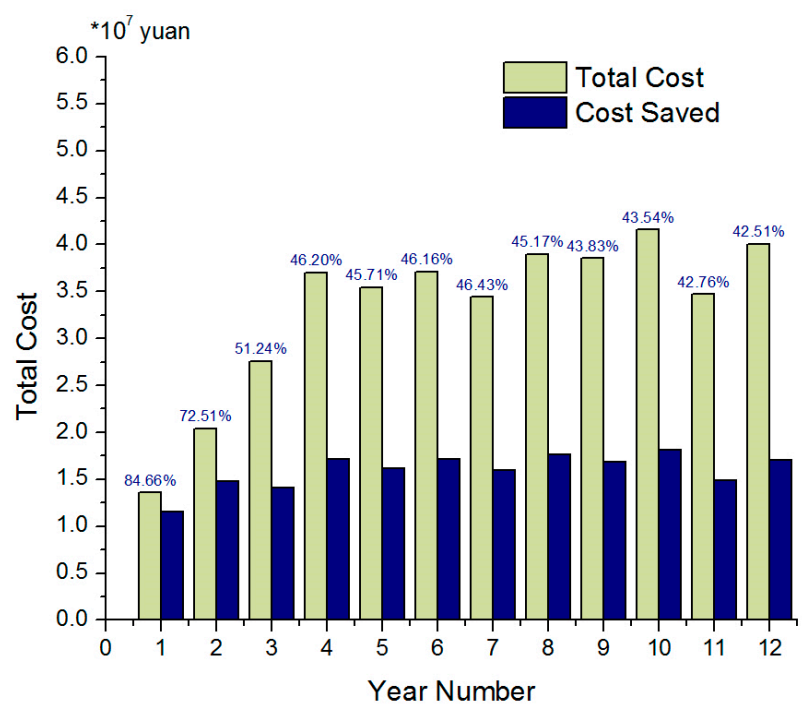

Figure 10. The costs of remanufacturing in the real case compared with manufacturing system. 
For example, the profit of fifth year is $6.728 \times 10^{6}$ yuan, to obtain this profit, the production costs of the remanufacturing system would be $3.545 \times 10^{7}$ Yuan, while the costs of manufacturing system would be $5.165 \times 10^{7}$ Yuan, saving the costs by $45.71 \%\left(\frac{5.165-3.545}{3.545} \times 10^{7} \times 100 \%=45.71 \%\right)$. In a similar way, Figure 11 shows the percentage of saved materials under the same profit in remanufacturing system when compared with manufacturing.

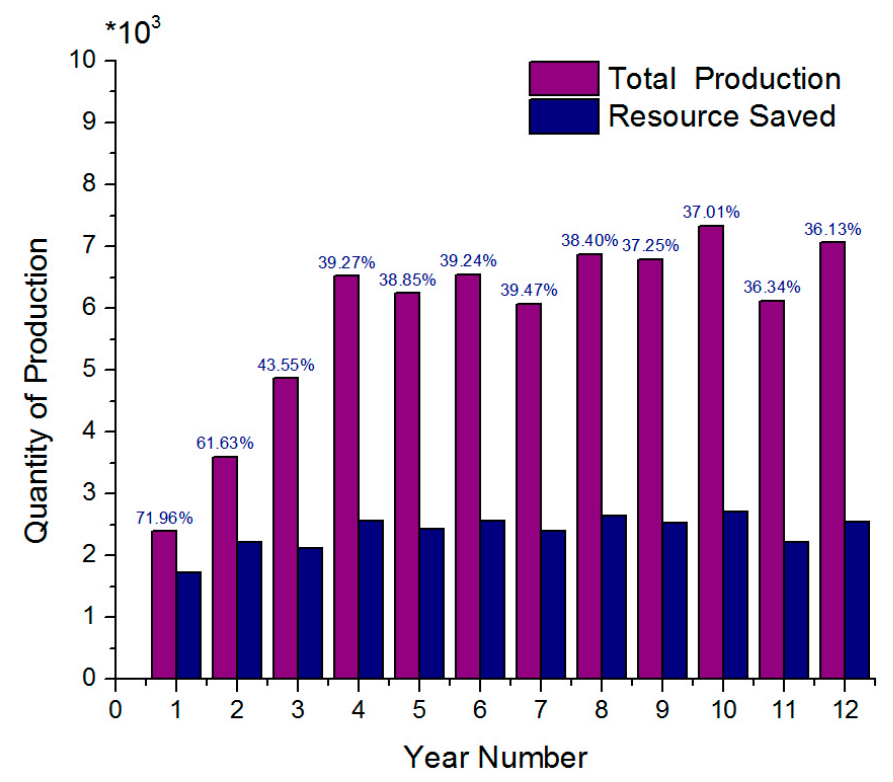

Figure 11. The resources consumed in remanufacturing in the real case compared with the manufacturing system.

Figure 11 shows, when under the same production, the resource savings in the real-life remanufacturing system compared to that of the single manufacturing system for each year.

Figure 12 shows, when under the same production, the material savings in the remanufacturing system in comparison with the single manufacturing system for each year.

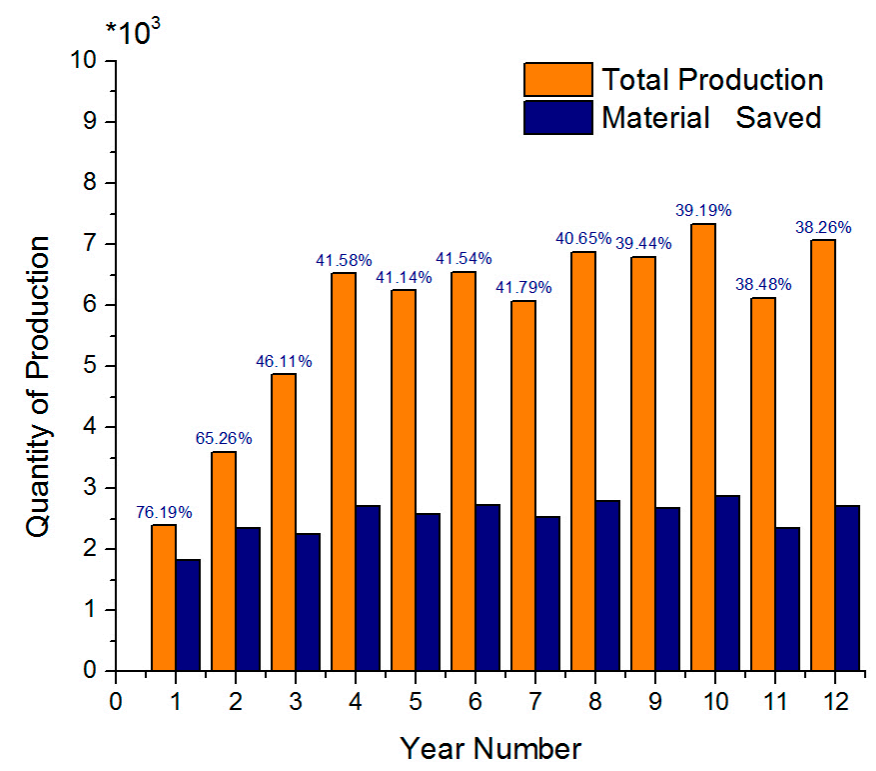

Figure 12. The quantity of remanufacturing in real case compared with manufacturing system. 
From the graphs above in Section 4.2.2 we can draw the conclusions as that, when comparing the remanufacturing with the original equipment manufacturing production, the results indicate a cost reduction of more than $40 \%$, a resource savings of more than $35 \%$, and a cost improvement of more than $40 \%$ could be achieved, this is consistent with conclusion that remanufacturing is environment-friendly and resource-saving than single manufacturing system.

In combination of the conclusions drew in Section 4.2.1, the standpoints of us can be summed up as follows: the profits and resource utilization rate of joint remanufacturing system in our model are higher than that of remanufacturing system in the real-life case; and that of remanufacturing system are higher than single manufacturing system.

\section{Conclusions and Discussion}

In this paper, a robust optimization approach was applied to analyze the optimal production policy for the joint automobile engine remanufacturing system. By setting up a quantified model we have calculated the effect of uncertainties in procurement and demand on net profit, resource saving, and material saving, and then developed a mathematical method to optimize the remanufacturing quantity regarding the procurement price, selling price, hosting cost and penalty cost. Then we applied the probability theory to analyze the effect of uncertainty on CLCS, developed the model where the quality level factor is a variable that shows a continuous change, and by the characteristics of remanufacturing we can conclude that the remanufacture cost changing trend is similar to that of the quality level factor, namely $C_{1}^{r}<C_{2}^{r}<C_{3}^{r} \ldots<C_{Q^{a}}^{r}$. Therefore, like the economic order strategy, there exists a remanufacture-up-to level that maximizes the profit of remanufacturing. By utilizing the central limit theorem, we have deduced the expression of this remanufacture-up-to level under the assumption of a binary distribution of the quality in procurement, then substituted that for the value of the remanufacture rate. Therefore, we obtained the optimum quantity of manufacture. In this paper we present the general deduction of the remanufacture-up-to level, and more detailed processes (such as assumptions, proofs, and relations) of it remain to be discussed in future research.

After deducing the remanufacture rate and the optimum quantity of manufacture we then analyzed the relationship between system variables, the result shows that the quality level analysis of procurement in the supply chain is very important for it has a direct impact on the strategy of production. To be more specific, it has direct impact on the quantity of both manufacture and remanufacture, on the total profit, and the net profit. By analyzing numerical experiments, we have illustrated the effects of uncertainty in system parameters, such as the manufacture ratio, salvage value, the broken probability of the supply chain in manufacture, unit manufacture/remanufacture cost, and hosting/penalty cost for the unit core.

Through the model established above, we applied it to a real-life case of an automobile engine remanufacturing factory, comparing the optimized result with its production situation, and have drawn two conclusions:

(1) The total profits can be boosted by about $20 \%$ (the first year) $-40 \%$ (the eleventh year) according to the production policy developed in our model.

(2) The average costs can be reduced by more than $25 \%$ according to the production policy developed in our theory model.

Meanwhile, we have also compared the result of remanufacture system in real-life case with that of single manufacture system on condition that other factors keep constant, and the following conclusions are drawn:

(1) Comparing the theoretic result of optimal joint remanufacturing policy with the production in the original equipment manufacturing, the results indicate that a cost reduction of more than $40 \%$ could be achieved when the optimal remanufacturing policy of our model is implemented.

(2) Under the same conditions, a resource saving of more than $35 \%$ could be achieved when the optimal remanufacturing policy of our model is implemented. 
(3) Similarly, a material savings of more than $40 \%$ could be achieved in the model of the joint remanufacturing system created above when compared with the production in the original equipment manufacturing.

The mathematical model of this paper is appropriate for a few occasions, such as the joint remanufacturing system in which the procurement and market demand are both stochastic, the yield rate is random, and there is the possibility of supply disruptions in a closed-loop supply chain. The results in this paper provide useful guidelines to firms whose market demand is uncertain and who face the risk of supply disruption in addition to uncertain volume and quality of returned items to make optimal decisions on determining the manufacturing quantity, while coordinating manufacturing and remanufacturing operations in their production processes.

The present study can also be extended in some ways.

(1) In this study, we assume the remanufactured products are completely the same as newly-produced products and sell them at the same price, and it will be meaningful to investigate the model in which the newly-produced products and remanufactured products have different demands and are sold at different prices.

(2) Additionally, for convenience's sake, the manufacturing and remanufacturing lead times have been assumed negligible. In future research, it could be taken into account.

(3) Furthermore, this study only considers the production in one lead time. In future research, it could be more interesting to apply a Markov process to the analysis of the joint remanufacturing system.

(4) Finally, in this study, we analyze the total profit with respect to the quantity of manufacture and the remanufacturing rate separately by assuming another variable is fixed to obtain the profit maximization. In future study, we should take the total profits as the function of two variables and use the partial derivative to obtain its optimum value.

Acknowledgments: This work was supported by the National Natural Science Foundation of China (71473077) and the National High Technology Research and Development Program of China (2013AA040206) and the National Key Technology R\&D Program of China (2015BAF01B00). We acknowledge all of the respondent Companies/Organizations. The authors would like to thank two anonymous reviewers for constructive comments to improve the paper quality.

Author Contributions: Qianwang Deng and Haolan Liao proposed the idea; Haolan Liao built the modeling, wrote the manuscript and designed the experiments; Yuanrui Wang and Haolan Liao analyzed the date.

Conflicts of Interest: The authors declare no conflict of interest.

\section{References}

1. Gehin, A.; Zwolinski, P.; Brissaud, D. A tool to implement sustainable end-of-life strategies in the product development phase. J. Clean. Prod. 2008, 16, 566-576. [CrossRef]

2. Wei, S.; Cheng, D.; Sundin, E.; Tang, O. Motives and barriers of the remanufacturing industry in China. J. Clean. Prod. 2015, 94, 340-351. [CrossRef]

3. Ramirez, E.; Gonzalez, R.J.; Moreira, G.J. Barriers and bridges to the adoption of environmentally-sustainable offerings. Ind. Mark. Manag. 2014, 43, 16-24. [CrossRef]

4. Maimoun, M.A.; Reinhart, D.R.; Gammoh, F.T.; Bush, P.M. Emissions from U.S. waste collection vehicles. Waste Manag. 2013, 33, 1079-1089. [CrossRef] [PubMed]

5. Tsiliyannis, C.A. Sustainability by cyclic manufacturing: Assessment of resource preservation under uncertain growth and returns. Resour. Conserv. Recycl. 2015, 103, 155-170. [CrossRef]

6. Kang, H.-Y.; Jun, Y.S.; Kim, Y.C.; Jo, H.J. Comparative analysis on cross-national system to enhance the reliability of remanufactured products. Procedia CIRP 2016, 40, 280-284. [CrossRef]

7. Chen, K.C.; Huang, S.H.; Lian, I.W. The development and prospects of the end-of-life vehicle recycling system in Taiwan. Waste Manag. 2010, 30, 1661-1669. [CrossRef] [PubMed]

8. Van der Laan, E.A.; Teunter, R.H. Simple heuristics for push and pull remanufacturing policies. Eur. J. Oper. Res. 2006, 175, 1084-1102. [CrossRef] 
9. Tsiliyannis, C.A. Internal cycle modeling and environmental assessment of multiple cycle consumer products. Waste Manag. 2012, 32, 177-193. [CrossRef] [PubMed]

10. Tian, J.; Chen, M. Sustainable design for automotive products: Dismantling and recycling of end-of-life vehicles. Waste Manag. 2014, 34, 458-467. [CrossRef] [PubMed]

11. Wei, H.; Jun, Y. Remanufacturing and benefits analysis of construction machinery hydraulic valves. China Surf. Eng. 2013, 26, 5.

12. Giri, B.C.; Sharma, S. Optimal production policy for a closed-loop hybrid system with uncertain demand and return under supply disruption. J. Clean. Prod. 2016, 112, 2015-2028. [CrossRef]

13. Koyanaka, S.; Kobayashi, K. Incorporation of neural network analysis into a technique for automatically sorting lightweight metal scrap generated by ELV shredder facilities. Resour. Conserv. Recycl. 2011, 55, 515-523. [CrossRef]

14. Ohno, H.; Matsubae, K.; Nakajima, K.; Kondo, Y.; Nakamura, S.; Nagasaka, T. Toward the efficient recycling of alloying elements from end of life vehicle steel scrap. Resour. Conserv. Recycl. 2015, 100, 11-20. [CrossRef]

15. Kim, T.; Glock, C.H. On the use of RFID in the management of reusable containers in closed-loop supply chains under stochastic container return quantities. Transp. Res. Part E Logist. Transp. Rev. 2014, 64, 12-27.

16. Hjaila, K.; Laínez-Aguirre, J.M.; Zamarripa, M.; Puigjaner, L.; Espuña, A. Optimal integration of third-parties in a coordinated supply chain management environment. Comput. Chem. Eng. 2016, 86, 48-61. [CrossRef]

17. Heiligers, B.; Ruf, J. Stochastic models for the return of used devices. In Advances in Stochastic Models for Reliability, Quality and Safety; Birkhäuser: Boston, MA, USA, 1998; pp. 113-123.

18. Guo, J.H.; Li, Y. Jointed pricing decision of remanufacturing system under uncertain demand. Syst. Eng. Theory Pract. 2013, 33, 1949-1955. (In Chinese)

19. Huang, Z.Q.; Zhang, B.Y. A stochastic inventory control model based on returned products permitted. In Proceedings of the 2007 International Conference on Wireless Communications, Networking and Mobile Computing, White Plains, NY, USA, 8-10 October 2007.

20. Konstantaras, I.; Papachristos, S. Note on: An optimal ordering and recovery policy for reusable items. Comput. Ind. Eng. 2008, 55, 729-734. [CrossRef]

21. Teunter, R.H.; Flapper, S.D.P. Optimal core acquisition and remanufacturing policies under uncertain core quality fractions. Eur. J. Oper. Res. 2011, 210, 241-248. [CrossRef]

22. Mukhopadhyay, S.K.; Ma, H. Joint procurement and production decisions in remanufacturing under quality and demand uncertainty. Int. J. Prod. Econ. 2009, 120, 5-17. [CrossRef]

23. Fang, Y.; Shou, B. Managing supply uncertainty under supply chain Cournot competition. Eur. J. Oper. Res. 2015, 243, 156-176. [CrossRef]

24. Kumar Jena, S.; Sarmah, S.P. Price competition and co-operation in a duopoly closed-loop supply chain. Int. J. Prod. Econ. 2014, 156, 346-360. [CrossRef]

25. Berzi, L.; Delogu, M.; Giorgetti, A.; Pierini, M. On-field investigation and process modelling of end-of-life vehicles treatment in the context of Italian craft-type authorized treatment facilities. Waste Manag. 2013, 33, 892-906. [CrossRef] [PubMed]

26. Goepp, V.; Zwolinski, P.; Caillaud, E. Design process and data models to support the design of sustainable remanufactured products. Comput. Ind. 2014, 65, 480-490. [CrossRef]

27. Rebitzer, G.; Köhler, A.; Suh, S.; Klöpffer, W.; Jolliet, O.; Saur, K. Theory and practical implementation of life cycle assessment. In Proceedings of the 13th SETAC-Europe Annual Meeting, Hamburg, Germany, 27 April-1 May 2003; pp. 235-240.

28. Tang, O.; Grubbström, R.W. Considering stochastic lead times in a manufacturing/remanufacturing system with deterministic demands and returns. Int. J. Prod. Econ. 2005, 93, 285-300. [CrossRef]

29. Kleineidam, U.; Lambert, A.J.; Blansjaar, J.; Kok, J.J.; Van Heijningen, R.J. Optimising product recycling chains by control theory. Int. J. Prod. Econ. 2000, 66, 185-195. [CrossRef]

30. Wee, H.-M.; Lee, M.C.; Jonas, C.P.; Wang, C.E. Optimal replenishment policy for a deteriorating green product: Life cycle costing analysis. Int. J. Prod. Econ. 2011, 133, 603-611. [CrossRef]

31. Marshall, S.E.; Archibald, T.W. Substitution in a hybrid remanufacturing system. Procedia CIRP 2015, 26, 583-588. [CrossRef]

32. Zolfagharinia, H.; Hafezi, M.; Farahani, R.Z.; Fahimnia, B. A hybrid two-stock inventory control model for a reverse supply chain. Transp. Res. Part E Logist. Transp. Rev. 2014, 67, 141-161. [CrossRef] 
33. Ahiska, S.S.; Appaji, S.R.; King, R.E.; Warsing, D.P. A markov decision process-based policy characterization approach for a stochastic inventory control problem with unreliable sourcing. Int. J. Prod. Econ. 2013, 144, 485-496. [CrossRef]

34. Fathi, M.; Zandi, F.; Jouini, O. Modeling the merging capacity for two streams of product returns in remanufacturing systems. J. Manuf. Syst. 2015, 37, 265-276. [CrossRef]

35. Perez, A.P.; Zipkin, P. Dynamic scheduling rules for a multiproduct make-to-stock queue. Oper. Res. 1997, 45, 919-930. [CrossRef]

36. Behret, H.; Korugan, A. Performance analysis of a hybrid system under quality impact of returns. Comput. Ind. Eng. 2009, 56, 507-520. [CrossRef]

37. Karaer, Ö.; Lee, H.L. Managing the reverse channel with RFID-enabled negative demand information. Prod. Oper. Manag. 2007, 16, 625. [CrossRef]

(C) 2017 by the authors. Licensee MDPI, Basel, Switzerland. This article is an open access article distributed under the terms and conditions of the Creative Commons Attribution (CC BY) license (http:/ / creativecommons.org/licenses/by/4.0/). 